\title{
Research on Customer Relationship Management in Software Industry Based on Multi-Agent
}

\author{
Hui Jiang ${ }^{1, a}$ Yuan Yuan Zhang ${ }^{1, b}$ \\ ${ }^{1}$ School of Management Science and Engineering, Shandong Institute of Business and Technology, \\ 264005 Yantai, China

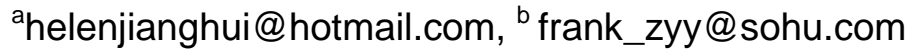

Keywords: Software industry; Customer relationship management; Agent technology; Multi-agent; Data analysis

\begin{abstract}
Currently many scholars and practitioners have studied the customer relationship management (CRM) theory, CRM has become a hot academic research. But for the software industry, research in this area is clearly insufficient. In order to meet the software industry on the need for intelligent analysis of customer relationships, to improve customer service quality, we analyzed the characteristics and needs of software companies' CRM system, used the multi-Agent technology and combined with CRM concepts, analyzed the software industry CRM system data features and system requirements, proposed the system framework of CRM in software industry based on Multi-Agent. Software companies can use this framework to build an effective customer relationship management system to achieve the marketing strategies and initiatively provide customers with personalized service, bring up the capabilities to improve customer satisfaction. In this study, we only studied the software industry CRM system, and we hope our study will bring some practical value to help China's software industry to improve their CRM work.
\end{abstract}

\section{Introduction}

Software industry is high-tech industry, its products have lag, invisible and reusability features. These features are different from traditional enterprise. So customer relationship management (CRM) plays an important role in the enterprise development strategy and directly affects the core c ompetitiveness of software enterprises.

In the era of service economy, software enterprises are facing transformation. CRM has graduall y become an important choice of software enterprises in transition period, this is different from the traditional enterprises.

From the point of computer science view, CRM is a set of customer data analysis system based on d atabase. From the perspective of management science, it is not only a set of software system, but als o reflect a kind of management concept, which takes the customer as the center. It can be said that CRM is the combination of client - focused management concept and computer technology. From $t$ he point of computer science view, CRM is a set of customer data analysis system based on databas e. From the perspective of management science, it is not only a set of software system, but also refle ct a client - focused management concept.

It can be said that CRM is the combination of client-focused management concept and computer technology. However, China's software enterprises, especially small and medium software companies, deployed CRM system implementation and implemented successful are very rare. On the one hand, the reason is CRM being trapped in experiencing from growing to maturity during the harsh market environment and weak technology; on the other hand it is restricted by the traditional enterprise management philosophy, management perspective and marketing ideas. Therefore, the software companies is more necessary and urgent to deploy CRM than other industry. 


\section{The main features of Agent Technology}

Agent is a software which can perceive the environment and take appropriate actions, and can set up their own action specification and affect environment change. Its main features are as follows.

(1) Intelligent. Agent integrates the model, knowledge, methods what required to complete its functions and tasks, also can accurately surmise user's intent and break down a complex task and provide targeted information for decision making.

(2) Collaboration. Agents coordinate through communication and cooperation in multi-Agent environment, digest conflict to perform and complete some tasks which one agent cannot solve.

(3) Learning. Agent as a separate entity, can self-learning and directly divert the user's interests, hobbies, habits and other information into an internal representation and stored in the knowledge base, then create a user model to guide decisions to conform to user needs.

(4) Initiative. Agent can actively analysis and get the user's personality information, potential de mand according to user's interest. Then agent take the initiative service.

\section{Customer relationship management system analysis in software industry}

Successful customer evaluation and information mining and brand value analysis can obtain complementary positive amplification effect in software product marketing, which is the special attention of the software companies in the development of marketing strategies to distinguish from the traditional enterprise. They are also effective ways the software enterprises in the fierce market competition to deal with the market demand risks for information lag. Then customer relationship management should face different industry, is a new platform to achieve the functions that traditional marketing model cannot achieve.

1. Data management Features

Software enterprises' customer relationship management system is a decision-support and information-service system, which can intelligent analysis of customer data and software data, assist decision-making, provide customers with personalized service, and oriented decision-makers, software developers and software users. The data management features are as follows.

(1) Data of software products is an important data source, contains the data of software products and software developers. The data of software products centralized for storage, using a combination of centralized and distributed client / server architecture.

(2) Through the registration information and relevant information produced in the development of the software product development process from time to time, analyze the structure of the composition of software products, regular patterns of the software development and the software needs of the users and other information, provide a convenient way for data collection.

(3) Data of customers focuses on the basic characteristics and changes in customer demand. We should effectively grasp the basic situation and changes in customer demand, in order to better meet customer needs.

2. System Requirements Analysis

(1) Collection of customer's information. Customers' personal information need to be timely, accurate and completely collected from the register of the product research and development.

(2) Establishment of a data warehouse. We should establish and update a data warehouse, and ultimately achieve a unified management of the software products and customers to effectively analysis, forecast and make intelligent decisions. 
(3) Customer behavior analysis. Using the data warehouse, the system should can analyze customer behavior through the customer's size, characteristics and needs. In accordance with changes in the target market, we can timely and accurately adjust the product and service strategies.

(4) Customer satisfaction analysis. By satisfaction analysis, we can understand the customers' attitudes and recommendations for software products and services, to help the software companies to adjust marketing strategies and increase the service level.

(5) Personalized service. There is a big difference in service needs between the different levels of customer, so system should be able to provide personalized service cater for different types of customers.

\section{System Framework Design}

Based on the above analysis, each functional module is configured for multiple intelligent Agent entity, and based on multi-Agent we proposed software enterprise customer relationship management system framework, shown in Fig.1. Entire frame is divided into five layers: user layer, portal layer, coordination layer, business management layer, and data management layer.

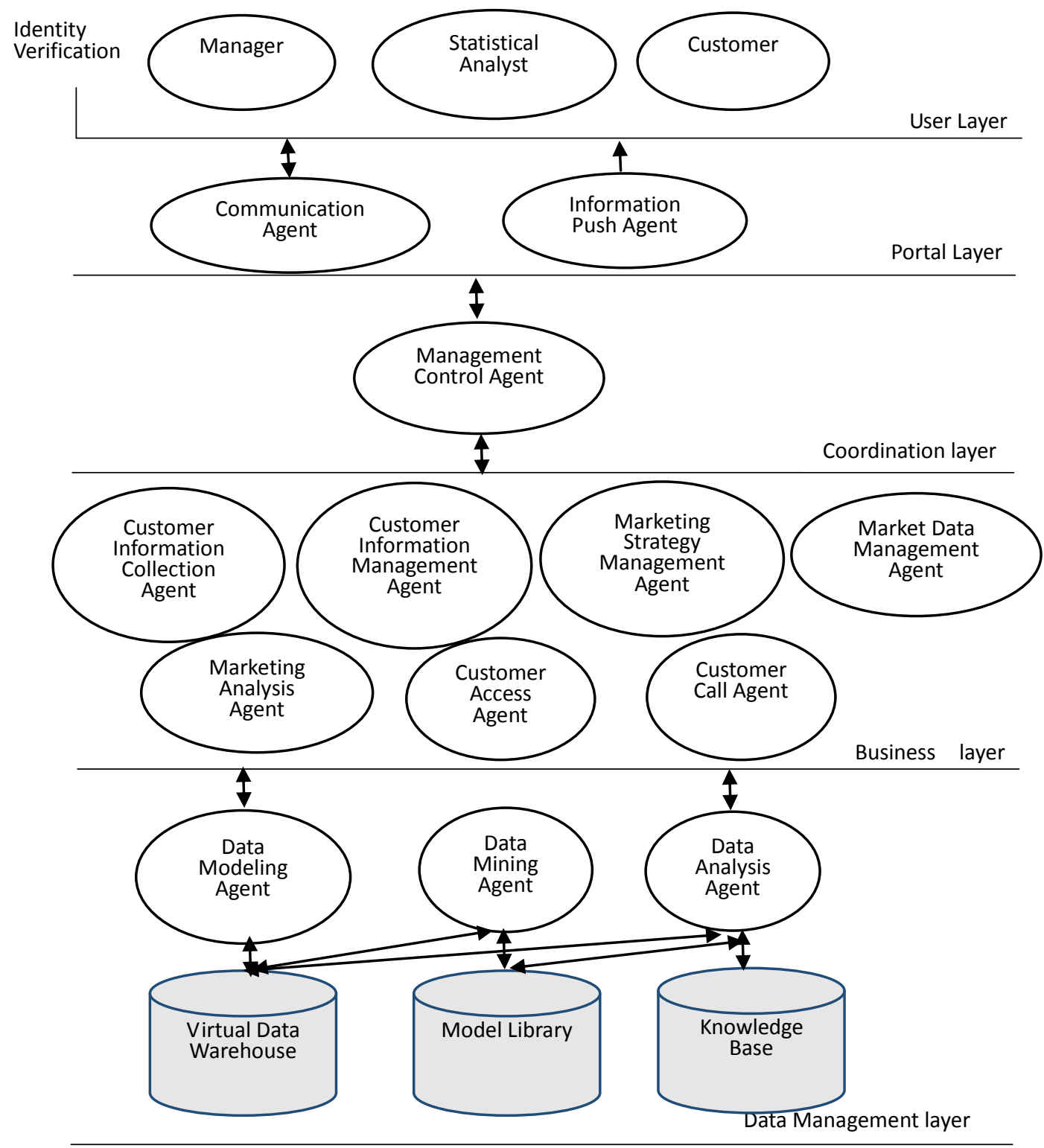

Figure 1 The system framework of customer relationship management in software industry based on Multi-Agent. 


\section{User Layer}

Users of this system include software management, statistical analysts and customers. Managements are responsible for making the right decisions for data analysis; statistical analyst are responsible for using data mining technology in data warehouse to find useful information to support decision making; customers can propose their business needs by accessing System through the network, e-mail, telephone, fax, etc. . Various types of user can receive personalized service by identity verification.

\section{Portal Layer}

Portal layer achieve the functions of human-computer interaction and pushing information initiatively, communicating with the coordination layer to disseminate and share information and distribute tasks. Users can login system in different authority, the system can push different information initiatively for different users.

Communication Agent helps to interact between human and computer, learn to get the user's personal preferences and buying patterns and other information from the user's interaction with the process. The results what the system obtained eventually are passed to the users to help users maximize the benefits. Information Push Agent can provide information services initiatively, which can track users' behavior and experience-based learning Agent and allow customers to follow their business needs to customize the service information.

\section{Coordination Layer}

Coordination layer is the information hub of the model. Management Control Agent receives what tasks the Communication Agent assigned and communicates with each Agent on the Business Management Layer, collaboratively completes the tasks submitted by users. After the user login system, Management Control Agent get user's information from the Communication Agent, and find out if there are information matched the user in the knowledge base, if he is our customer already we can use the existing information and call the services in the knowledge base; if he is a new customer, management control Agent extracts the user's business needs, and the relevant Agent on business management layer will be assigned collaborative tasks to complete the customer's service.

\section{Business layer}

Business Layer contains customer information management module, marketing module and service module. Customer information management module consists of two parts: user information collection Agent and customer information management Agent. Marketing module includes marketing strategy management Agent, marketing analysis Agent and market data management Agent. Service module includes access services and outbound services Agent, providing a unified service interface to provide users with personalized, intelligent service.

\section{Data Management Layer}

This layer including customer analysis module, the data modeling Agent, data mining Agent and data analysis Agent. These Agents composites to provide various types of data analysis service for the system, to provide a basis for decision support.

\section{Conclusion}

Through intelligent data analysis of customer relationship management in software industry, software companies can develop service strategies for the different needs of their customers, then improve the Quality of service in software industry. For this reason, we supplied the system framework of customer relationship management in software industry based on Multi-Agent. Software companies should apply the concept of customer relationship management and use this 
framework to construct a system for each functional module as Smart Agent. Collaboration among Agent can complete the task presented by the customer, so software companies can make statistical analysis to realize the marketing strategy and initiative to provide customers with personalized service.

\section{Acknowledgement}

This work is supported by Shandong Province humanities and social Sciences project (J13WG62).

\section{references}

[1] Columbus, Louis (2013), "Roundup of CRM Forecasts and Market Estimates, 2012," Forbes, (accessed December 16, 2013), [available at http://www.forbes.com/sites/louiscolumbus/2012/12/04/roundup-of-crm-forecasts-and-market-esti mates-20121]

[2] Bharadwaj, A. (2000). A resource-based perspective on information technology and firm performance: An empirical investigation. MIS Quarterly, 24, 169-196.

[3] Álvarez, L. S., Casielles, R. V., \& Martin, A. M. D. (2010). Analysis of the role of complaint management in the context of relationship marketing. Journal of Marketing Management, 27(1-2), 143-164.

[4] Amonini, C., McColl-Kennedy, J. R., Soutar, G. N., \& Sweeney, J. C. (2010). How professional service firms compete in the market: An exploratory study. Journal of Marketing Management, 26(1-2), 28-55.

[5] Harrigan, P., Ramsey, E., \& Ibbotson, P. (2011). Critical factors underpinning the e-CRM activities of SMEs. Journal of Marketing Management, 27(5-6), 503-529.

[6] Hussain, I., Hussain, M., Hussain, S., \& Sajid, M. A. (2009). Customer relationship management: Strategies and practices in selected banks of Pakistan. International Review of Business Research Papers, 5(6), 117-132.

[7] Jarratt, D. G., \& Katsikeas, C. S. (2009). How does relationship management infrastructure influence performance? Journal of Marketing Management, 25(1-2), 51-74.

[8] Yin, R.K. (2008). Case study research: Design and methods. Thousand Oaks, CA: Sage.

Reference to a book:

[9] Blattberg, R. C., Getz, G., \& Thomas, J. S. (2001). Customer equity: Building and managing relationships as valuable assets. Boston, MA: Harvard Business School Press.

Reference to a chapter in an edited book:

[10] Buttle, F. (2004). Customer relationship management: Concepts and tools. Oxford: Elsevier/Butterworth Heinemann. 